\title{
LOS PRINCIPIOS GENERALES DEL DERECHO Y LA JUSTICIA
}

\author{
José Manuel Fernández Hierro
}

\begin{abstract}
No creo que nuestros edictos sean tan importantes
Como para que un hombre mortal rechazase

Las leyes no escritas e inmortales de los dioses

Cuya vida no es de hoy o de ayer

Sino de siempre y nadie sabe de dónde provienen

No me expondría al castigo de los dioses

Quebrantando estas leyes por temor a ningún hombre.
\end{abstract}

Sófocles, Antígona, 450-460.

Sumario: 1. Planteamiento. 2. La justicia a través del tiempo. 3. Los principios generales del derecho. 4. Conclusiones.

\section{Planteamiento}

Las palabras «derecho»y «justicia» son frecuentemente utilizadas, y las expresiones «tengo derecho a», «no es justo», «es una injusticia» y otras más, se usan en el lenguaje diario por la mayoría de los ciudadanos y son frecuentes oírlas o leerlas en los medios de comunicación social. Pero paradójicamente la voz justicia, tan usada, es una de las que han resultado más difíciles de definir ${ }^{1}$, tal vez por las acepciones encontradas que a la misma se han dado y por la pluralidad de significados que de la misma se puede encontrar:

No es ninguna novedad el resaltar la ambigüedad del concepto de justicia que ya en su día observó Aristóteles²:

«Ahora bien, justicia e injusticia parecen ambiguos pero como sus significados diferentes se aproximan uno al otro la ambigüedad pasa inadvertida, no siendo tan claro y manifiesto como es, comparativamente cuando los significados están muy alejados».

\footnotetext{
1 Ya advertía IsOCRATES (Contra los sofistas XII-21) que la justicia no es cosa enseñable aun cuando debe ser practicada.

2 Etica a Nicómaco, libro V, capítulo 1.․
} 
En nuestros días ha subrayado Kelsen ${ }^{3}$ :

«En consecuencia, la ciencia del derecho no puede declarar que tal orden $-\mathrm{o}$ tal norma jurídica - es justo o injusto, pues tal juicio se funda, ya sea en una moral positiva, es decir en un orden normativo diferente e independiente del derecho positivo, o en un verdadero juicio de valor con carácter subjetivo.

Además la idea de la justicia no se presenta casi nunca como un valor relativo, fundado sobre una moral positiva establecida por la costumbre, y por esta razón diferente de un lugar a otro, de una época a otra. En su sentido propio la idea de justicia es un valor absoluto, un principio que pretende ser válido siempre y en todas partes, independientemente del espacio y del tiempo: es eterna e inmutable. Ni la ciencia del derecho positivo ni ninguna otra ciencia pueden determinar su contenido, que varía al infinito».

Y si algo parecido nos sucede con la palabra derecho el encontrar los principios generales del mismo no es tampoco tarea fácil, como tampoco el ver la relación que en los principios generales de derecho puedan tener con el derecho o con la justicia en abstracto, aun cuando, si aceptamos la teoría de Wittgestein ${ }^{4}$, dado que podemos formular la pregunta debemos responderla.

La modificación del título preliminar del Código Civil y la entrada en vigor de la Constitución pudieron dar nuevos datos para una polémica más centenaria. En estas páginas voy a tratar de sintetizar y resumir la relación entre los anteriores conceptos.

\section{La justicia a través del tiempo}

La Biblia tiene una elevada consideración de la justicia:

«Y de la justicia haré regla y del derecho haré mi ley ${ }^{5} »$.

La justicia nos señala el camino ${ }^{6}$ :

«Entenderás entonces justicia, juicio, equidad, en suma buen camino».

Sin embargo si se tiene un alto concepto de la justicia y se reitera en numerosos pasajes la necesidad de la misma, no aparece un claro

\footnotetext{
${ }^{3}$ Teoría pura del derecho, Buenos Aires, 1973, pp. 60 y ss.

${ }^{4}$ Tractatus logicus filosoficus, n. $^{\circ} 6.5$.

5 IsAÍAS, 28-17.

6 Proverbios 2-8.
} 
concepto de la misma: se insiste en que hay que practicar la justicia y guardar el derecho ${ }^{7}$ pero el contenido de la misma no es enumerado con nitidez.

Tal vez una de las citas más detalladas es la que se contiene en el libro de Ezequiel ${ }^{8}$ :

«El que sea justo y haga justicia, no banquetee por los montes, y no alce sus ojos a los ídolos de la casa de Israel, no manche a la mujer de su prójimo, y no llegue a la menstruada, que no time a nadie y devuelva al deudor su prenda, y no robe y dé pan al hambriento y vestido al desnudo, no dé a logro ni reciba a usura, retraiga su mano del mal, y haga juicio de verdad entre hombre y hombre, camine mis mandatos, obre mis leyes obrando rectamente, ése es justo, vivirá, dice Yavéh».

De la cita transcrita se deriva que el concepto de justicia para el Antiguo Testamento está íntimamente ligada con el de religión y, en definitiva, la justicia supone el cumplimiento de una serie de deberes, que si bien afectan en ocasiones a las relaciones de una persona con los demás, pueden también referirse exclusivamente a la relación de la propia persona con Dios.

«Esta idea (la de la justicia) desempeña un papel importante en el Antiguo Testamento y comprende no sólo la estricta justicia aristotélica sino la totalidad de los deberes civiles del hombre. El concepto israelita de justicia se aproxima, pues, a nuestras ideas de santidad, piedad, integridad y rectitud» (...) «Justo es aquél que vive conforme al beneplácito de Yavéh (Génesis 6,9 y 7,1) que sigue la ley de Yavéh (Isaías 3,10 Ezequiel 3,20 $)^{9} \gg$.

A pesar de ellos y sin que suponga contradicción con lo anterior, en determinados pasajes bíblicos la justicia tiene un significado parecido a su acepción corriente actual: así cuando se señala que «tendrás pesas cabales y justas, medidas cabales y justas» ${ }^{10}$ y cuando se indica: «oíd a vuestros hermanos, juzgad según justicia las diferencias que pueda haber entre ellos o con extranjeros» ${ }^{11}$; pero, en conjunto, el sentido del Antiguo Testamento es el señalado de justicia como rectitud o santidad $^{12}$.

7 ISAÍAS 56-1.

8 EZEQUiEl 18. 5-9.

9 H. HaAg y A. Van Den Born, Diccionario de la Biblia, Barcelona, 1963, p. 1.057.

10 Deuteronomio 25, 15.

11 Deuteronomio 1, 16.

${ }^{12}$ Véase Descamp, «Justicia» en Vocabulario de teología bíblica. Barcelona, 1973, pp. 460 y ss. 
La evolución sufrida a lo largo de la historia por el judaísmo no afectó a este concepto (aun cuando sí puede hablarse de un cambio importante en el Nuevo Testamento, sobre todo en los escritos paulinos, en el que las referencias a la justicia cambian de sentido acercándose al concepto de justificación por la $\mathrm{fe}^{13}$ ) sino, tal vez, al contrario:

«Los profetas critican la praxis jurídica de los que mandan, el desprecio del derecho por las clases altas, las omisiones y transgresiones de funcionarios y jueces que declaran inocentes a los culpables, condenan a los inocentes, dejan en la estacada a huérfanos y viudas en lugar de preguntarse por el sentido y el espíritu del derecho y dejar que hable el corazón en aplicación de la Ley ${ }^{14}$.

Tal concepción no fue única de la Biblia. Así en el antiguo Egipto:

«La Justicia no es una noción relativa; no depende de los hombres sino del Ra que fija sus reglas, la justicia es una cosa divina y por lo mismo está representada por una diosa Maat, hija del gran dios creador, en otras palabras la justicia emana directamente de Dios: "La justicia es grande, invariable, segura y no ha sido turbada desde la época de Osiris" que la dio a conocer a los hombres. "Los límites de la justicia son invariables, es una enseñanza que cada hombre adquiere de su padre", pero si es verdad que emana de Dios entre los hombres se traduce por la Ley. Por consiguiente, la ley se impone a los hombres como una obligación moral. Es la base del orden social, de la propiedad: "oponer obstáculos a la ley es abrir la puerta a la violencia". No es posible que un hombre pueda decir: "Yo me apodero de esto porque es mi deseo» sino que dirá: "Lo tomé porque es mi derecho ${ }^{15}$ "》.

Y lo mismo sucede en la antigua Mesopotamia ${ }^{16}$ :

«Amin y Enlil me señalaron a mi Hammurabi, príncipe piadoso, temeroso de mi dios, para proclamar el derecho en el País, para destruir al malvado y al perverso, para impedir que el fuerte oprimiera al débil».

Platón fue probablemente el filósofo que en la antigüedad dedicó más páginas al tratado de la justicia en varias de sus obras, ya que según señala no hay crimen mayor contra la ciudad que cometer injusticia con ella ${ }^{17}$.

13 Véase López Aranguren, «Catolicismo y protestantismo como formas de existencia» en Obras, tomo 1, pp. 266 y ss. Madrid, 1965.

${ }^{14}$ Hans Kung, Judaísmo, Barcelona, 1994, p. 128.

15 Pirenne. Historia del Antiguo Egipto, tomo 1, p. 251.

16 Código de Hammurabi, versículos del 20 al 40. Véase tambien Brice PARAIn, Historia de la Filosofía, V.I., «El pensamiento prefilosófico y oriental», Madrid, 1969, p. 41.

17 En La república, libro 4. ${ }^{\circ}, \mathrm{X}, 434 \mathrm{C}$. 
Sin embargo su concreción tampoco es clara, aunque de algunos pasajes de Platón parece deducirse que la justicia es la aplicación práctica de las normas de la ciudad ideal que él había diseñado ${ }^{18}$.

Para Aristóteles hay que puntualizar como:

«Observemos que todos entienden por justica el hábito que hace que las personas se hallen en disposición de efectuar lo justo, inclinándoles a obrar justamente y desear lo justo; y del mismo modo entienden por justicia el hábito que les hace obrar injustamente y desear lo injusto ${ }^{19}$ ».

El Derecho Romano relacionó derecho y justicia hasta el punto de que en su versión clásica el derecho es precisamente el arte de lo justo y de lo injusto, y de que el ius es, de acuerdo con la conocida definición de Celsol ars boni et aequi.

Cicerón señaló como base de la justicia:

«Fundamentum autem es iustitiae fide, id est dictorum conventorum constantia et veritas ${ }^{20} »$.

La otra definición clásica contenida en el Digesto enlaza la justicia con el derecho de cada uno:

«Iustitia est constans et perpetua voluntas ius suum cuique tribuere ${ }^{21} \gg$.

La idea de la justicia ha ido ligada con el iusnaturalismo a través de la tradición aristotélica y medieval ${ }^{22}$, y posteriormente de Grocio y los autores de las escuelas holandesa y española del derecho natural, hasta la reacción positivista contra éste.

Se ha señalado que precisamente la característica del positivismo es la negación del derecho natural, limitándose, como su nombre indica, al derecho positivo emanado de las autoridades competentes: para el positivismo puro el fundamento último del derecho está en el poder del estado y no tiene ningún fundamento metajurídico.

Por tanto el positivismo combatió la idea de la justicia abstracta y enlazó los principios generales del derecho, con los del derecho positi-

18 Obra citada, libro 4. ${ }^{\circ}, \mathrm{Xl}, 434 \mathrm{C}$.

19 Etica a Nicómaco, libro V, cap. I.

20 De officiis, 1,7

${ }^{21}$ Digesto, 1, 1, 10. En análogo sentido Instituciones 1.1. La equivalencia entre derecho natural y justicia la encontramos en Digesto $1,1,11$.

${ }^{22}$ La idea del derecho natural la encontramos en ArIstóteles, Etica a Nicómaco, libro $\mathrm{V}$, capítulo VII. 
vo vigente, obteniendo un notable éxito en su empresa ${ }^{23}$, ya que como señala Radbruch ${ }^{24}$ :

«Si nadie es capaz de fijar lo que es justo, alguien tiene que establecer lo que sea el Derecho».

Para buscar una justificación al ordenamiento jurídico Stammler acuñó la expresión de derecho justo: ahora bien, para Stammler el derecho justo es el derecho establecido, el derecho positivo con lo cual el parámetro para medir de la justicia de un derecho es la coherencia de la norma con el ordenamiento jurídico ${ }^{25}$. Con tal posicionamiento trató de crear una vía intermedia entre la idea del derecho natural y el positivismo, aunque tal vez inclinándose hacia el positivismo, si bien señalaba que el impulso con lo justo es consustancial con la existencia misma del derecho ${ }^{26}$.

Algunos ordenamientos jurídicos recogen expresamente esta concepción: así el artículo 12 del Código Civil Italiano de 1942 alude a la aplicación de la ley según la intención del legislador y a los principios generales del ordenamiento jurídico de Estado; y el artículo 8 del Código Civil Portugués señala que el deber de obediencia a la Ley no puede ser contrarrestado por la alegación de que ésta es injusta o inmoral.

Sin embargo, después de la Segunda Guerra Mundial los hechos en ella cometidos, en especial el descubrimiento de las atrocidades nazis, impulsaron un resurgimiento del concepto de justicia abstracta, dado que si el único concepto del derecho era el del derecho vigente no había parámetro para medir y condenar tales actuaciones, que se ajustaban en un todo a la legalidad vigente y a los principios generales del derecho derivados de esa legalidad por muy repugnantes que parecieran.

En nuestro país, De la Vega Benayas ${ }^{27}$ ha sido partidario de que el juez pueda decidir contra la ley partiendo de su deber de dictar una decisión justa.

Hans Kelsen ha criticado la vuelta al naturalismo señalando que:

«La justicia absoluta es un ideal irracional. Por indispensable que pueda ser a la voluntad y a la acción escapa al conocimiento racional y

23 O en todo caso del Derecho Romano como quería Del VeCCHIO, en Los principios generales del derecho, Barcelona, 1979, pp. 43 y ss.

${ }^{24}$ Citado por Welzel, «El problema de la validez del derecho», en Derecho injusto y el derecho nulo, Aguilar, Madrid, 1971, p. 102.

25 Véase Karl Larenz, Derecho justo. Fundamentos de ética jurídica, Cívitas, Madrid, 1985, pp. 21 y sigs.

${ }^{26}$ StammLer, Die Pehre Von Richtigen Rochte, p. 57, citado por LARENZ en obra citada, p. 28.

27 Introducción al Derecho judicial, Madrid, 1970, p. 240. 
la ciencia del derecho sólo puede explorar el dominio del derecho positivo. Cuanto menos nos empeñamos en separar netamente el derecho de la justicia, en mayor grado mostramos indulgencia con respecto al deseo del legislador de que el derecho sea considerado como justo y más cedemos a la tendencia ideológica que la caracteriza la doctrina clásica y conservadora del derecho natural. Esta doctrina no busca conocer el derecho en vigor como justificarlo y transfigurarlo destacando que emana de un orden natural, divino o racional; por lo tanto absolutamente justo y equitativo. La doctrina revolucionaria del derecho natural, que desempeña en la historia de la ciencia del derecho un papel relativamente oscuro, tiende al fin opuesto. Pone en duda la validez del derecho positivo, afirmando que está en contradicción con un orden absoluto cuya existencia postula. Presenta así al derecho bajo una luz que lo hace aparecer a veces mucho más imperfecto de lo que es en reali$\operatorname{dad}^{28} \gg$.

Cualquiera de los puntos de vista que adoptemos tiene sus limitaciones: la opción de un criterio de justicia trascendente al derecho positivo nos puede abocar a una inseguridad jurídica, mientras que el criterio contrario nos conduce a aceptar las pautas señaladas por el legislador, fueran las que fueran. Aun cuando los dos criterios tienen sus inconvenientes, es más grave el de aceptar indiscriminadamente los principios que siente el legislador positivo por muy aberrantes que fueran.

Para tratar de superar estos problemas se ha caracterizado a la justicia como igualdad y como imparcialidad, cuyo antecedente está en Aristóteles $^{29}$. Rawls, uno de los autores modernos que más ha profundizado este problema, señala:

«La justicia con imparcialidad comienza, como he dicho, con una de las selecciones más generales que las personas pueden hacer en común, esto es con la elección de los primeros principios de una concepción de la justicia, que habrá de regular toda la crítica y reforma subsecuente de las instituciones. Por tanto, después de haber escogido una concepción de la justicia, podemos suponer que escogerán una constitución y un poder legislativo que promulge las leyes, de acuerdo siempre con los principios de la justicia convenidos originariamente. Nuestra situación social es justa si a través de esta secuencia de acuerdos hipotéticos hubiéramos convenido un sistema general de reglas que la definie$\operatorname{ran}^{30} \gg$.

8 Obra citada, pp. 62 y ss.

Etica a Nicómaco, libro V, capítulo III.

30 Teoría de la justicia, Madrid, 1978, p. 30. 
Si bien la justicia entendida de manera formal se ha ligado fundamentalmente al concepto de igualdad, hay que tener en cuenta que tal aplicación no puede ser automática porque sólo partiendo de supuestos y situaciones equivalentes se puede hablar de igualdad de trato. Continúa diciendo Rawls:

«Esta idea de la justicia ligada a la igualdad en cuanto al debe, sin duda alguna, mucho a la asociación de la justicia con los procedimientos jurídicos. Se supone que la Ley ha de ser aplicada igualmente en todas las situaciones y a todas las personas a las que se refiere sin miedo ni favor; a ricos y a pobres, a poderosos y a humildes por igual, se puede considerar la encarnación de la justicia a aquella ley que se aplica sin discriminación alguna. Lo que también ha de subrayarse es que la justicia en este sentido no es realmente más que un principio formal de igualdad. Ni siquiera puede considerársela un principio de igualdad sin más cualificación. La justicia no puede significar tampoco que vamos a tratar a todos del mismo modo sin tener en cuenta las diferencias individuales, porque eso nos obligaría, por ejemplo, a condenar con la misma pena a todo aquel que haya matado a una persona, sin tener en cuenta factores tales como la incapacidad mental, o la minoría de edad del acusado. Lo que este principio significa realmente es que los semejantes sean considerados como semejantes, por lo que todo aquel que esté clasificado como perteneciente a la misma categoría, en relación con un objetivo particular, será tratado de la misma manera».

Y en el mismo sentido puntualiza Lloyd:

«La idea de justicia encarnada en el principio de tratar casos semejantes de un mismo modo parece implicar cuando se amplía tres concepciones relacionadas: primero que habrá normas establecidas de cómo debe tratarse a la gente en casos dados; segundo, que estas normas serán de carácter general, es decir, que dispondrán que todo aquel que entre en el marco de una norma será regido por ésta. (En otras palabras, debe aplicarse o bien de un modo general a todas las personas, o bien a ciertas categorías de persona especialmente definidas, y no individuos al azar). En tercer lugar la justicia requiere que estas normas generales sean aplicadas imparcialmente, es decir, que los órganos encargados de administrarlos las apliquen sin discriminación, ni miedo, ni favor, a todos aquellos que entren en el marco de las normas ${ }^{31}{ }^{1}$.

Como antes he indicado la primera distinción que hay que mantener es la de justicia material y justicia formal, ya que la que constituye un desarrollo de la idea de igualdad es la justicia formal como señala Latorre ${ }^{32}$ :

\footnotetext{
31 La idea del derecho. ¿Perversidad represora o justicia social? Madrid 1985, p. 132.

32 Justicia y derecho, Barcelona, 1973, p. 23.
} 
«Así, la idea de justicia lleva aparejada la de "igualdad". Los casos iguales habrán de ser valorados de igual modo y los desiguales de desigual manera. Si en un examen dos estudiantes demuestran igual preparación, todos consideramos justo que obtengan la misma nota. Pero si uno hace un examen mejor que otro nos parecerá así mismo justo que aquél obtenga una nota más alta. La igualdad y por tanto, la justicia, supone que si una regla debe regir para todos, nadie puede infringirla en beneficio propio y perjuicio ajeno».

Ciertamente ello es así en cuanto al aspecto formal de la justicia que sería infringido cuando se trata con distintas varas de medir situaciones iguales. Pero sin embargo, difícilmente con ello podemos llenar el contenido material de la justicia: siguiendo el ejemplo de Latorre podemos entender que es injusto el suspenso del estudiante que ha hecho igual el examen que otros que han aprobado (aspecto de la igualdad como contenido formal de la justicia), pero tal ejemplo no nos vale para señalar cuando debemos aprobar al segundo estudiante, o si un ordenamiento jurídico es justo o no.

Pensemos también en una hipotética norma que impusiera la eutanasia a todas las personas al cumplir una determinada edad: tal norma difícilmente podría ser tachada de injusta con la sola invocación del principio de igualdad. Para denunciarla habría que acudir a principios que estuvieran por encima de la misma.

¿Se podría entender que los principios de la justicia son los mismos que los de la moral? Derecho y moral son distintos, y como señala Legaz y Lacambra ${ }^{33}$ el derecho no existe para la persona íntima, sino sólo para la persona social o socializada.

El punto de mira del derecho y la moral son diferentes y por tanto, aun cuando parcialmente coincidentes, tales principios metajurídicos no pueden serlo de la moral: el ciudadano debe saber distinguir entre lo que es ilícito y lo que es moral, y que se trata de dos parámetros que no tienen por que coincidir, aunque el derecho sea el óptimo posible.

$\mathrm{Y}$ no solamente no coinciden en cuanto a su objeto (la actuación global del hombre en la moral y la actuación externa de éste, en cuanto tenga relación con los demás en el derecho distinción que se remonta a Santo Tomás ${ }^{34}$ ) sino que incluso dentro del campo común las soluciones de ambos pueden ser distintas: pensemos en la prescripción extintiva, por ejemplo que, en aras de la seguridad jurídica, introducen casi todos los ordenamientos positivos, prescripción que sería inexistente en el campo moral.

\footnotetext{
${ }^{33}$ Horizontes del pensamiento jurídico, Barcelona, 1947, p. 95.
}

${ }^{34}$ Summa theologica II-AE, 157, A1. 
Ello no es óbice tengamos en cuenta, como acertadamente observa Legaz y Lacambra ${ }^{35}$ que es difícil separar hombre jurídico y hombre moral; y aunque la situación de asignar la moral a la conciencia individual y el derecho al ordenamiento estatal en opinión de De los Mozos ${ }^{36}$ no se atiene a la esencia y alcance de uno y otro y desconoce de alguna forma la tradición culta que debe anteceder a la formulación de cualquier obra legislativa, una cosa es que la moral haya influenciado en la formación del derecho en nuestro sistema jurídico y otra diferente es hacerlo coincidente ${ }^{37}$.

Tales principios podrían ser los del propio ordenamiento jurídico en su «impulso hacia lo justo» que señalaba Stammler; pero para ello hace falta que del conjunto del ordenamiento jurídico puedan estarse unos principios que justifiquen la calificación de injusta a una ley determinada.

Las referencias a lo que debe entenderse materialmente por derecho justo no son fáciles de encontrar.

Prueba de tal imprecisión son las conclusiones que extrae Dennis Lloyd:

«Existen dos formas principales en que un sistema jurídico puede aspirar a alcanzar no sólo la justicia puramente formal, sino también sustancial, en la medida en que se reflejan en el sistema de valores que actúa en una comunidad en particular. De las dos, la primera es más limitada, pero es de alguna forma más penetrante a largo plazo. Se trata de impartir una cierta flexibilidad a los tribunales y los órganos de la administración de justicia a fin de conferir a los jueces y a los demás funcionarios legales la posibilidad de desarrollar la Ley y adaptarla a las necesidades de la sociedad en que actúa, y otro fijar la inclusión de los derechos en normas fundamentales constitucionales, las cuales no descartan el iusnaturalismo entre otras por los términos originales en que están concebidos y que dejan margen amplio para interpretaciones contradictorias e incluso a nivel judicial» ${ }^{38}$.

Sin gran éxito Herbada ${ }^{39}$ señala para salvar esta dificultad que la justicia consiste en dar a cada uno su derecho, solución más aparente que real porque si el dar a cada uno su derecho viene determinado por

35 Introducción a la ciencia del derecho, Barcelona, 1943, p. 224.

36 «El derecho natural en la formación de derecho civil» en Revista de Derecho Privado, abril 1969, p. 245.

37 Véase al respecto Soto NiETo, «Coincidencia y diferenciación práctica del derecho y la moral» en Cuestiones jurídicas. Jurisprudencia creadora, tomo I, pp. 17 y ss.

${ }^{38}$ Obra citada, p. 146.

${ }^{39}$ Lecciones de Filosofía del derecho, teoría de la justicia del derecho. Pamplona, 1989, p. 113. 
éste, difícilmente podremos tachar al ordenamiento de injusto a no ser que acudamos a un conjunto de normas supralegales, como hace Herbada con el derecho natural.

Tal solución es posible, y es más, como queda reflejado a lo largo de estas páginas, el derecho natural ha tenido una importante revalorización en el pensamiento jurídico de la segunda mitad del siglo Xx; pero en esta hipótesis habrá que convenir con Lumier ${ }^{40}$ que la búsqueda de la justicia está más allá del derecho, o, al menos, del derecho positivo:

«El problema de la justicia es el problema de la búsqueda de criterio en base al cual pueden valorarse como justas o injustas una conducta determinada y la norma en que ésta aparece inspirada. Es decir, la justicia no es más que un criterio de valoración o, como se suele decir más brevemente, un valor, y precisamente el valor se realiza a través del apartado del Derecho. El problema de la justicia no es otra cosa que el problema de los valores jurídicos, de su fundamento y de sus contenidos. De ahí resulta manifiesto que está íntimamente ligado al problema de los valores en general pues, en definitiva, no es más que un aspecto particular de su problema y por ello debe ser estudiado con referencia a él».

Ciertamente la aceptación del derecho natural puede ser una solución y un punto de apoyo más allá del derecho positivo ${ }^{41}$; el problema estaría en las controversias sobre el relativismo o universalismo del derecho natural y la difícil obtención en él de respuestas claras y unívocas y universales a cualquier punto jurídico que se plantee. Por eso se ha tratado de buscar otros esquemas como básicos de la justicia; esquemas fundados en la organización más racional de la vía en común. Así para Rawls ${ }^{42}$ los principios de la justicia serían:

«Primero: Cada persona ha de tener un derecho igual al esquema más extenso de libertades básicas iguales que sean compatibles con un esquema semejante de libertades para los demás.

Segundo: Las desigualdades sociales y económicas habrán de ser conformadas de modo tal que a la vez que:

a) Se espere que sean ventajosas para todos.

b) Se vinculen a empleos y cargos asequibles para todos».

40 Principios de teoría e ideología del derecho, Madrid, 1985, pp. 114 y ss.

41 No en vano se ha señalado que el núcleo del iusnaturalismo moderno son los derechos del hombre como persona moral. Así lo indica Helmut CoING en Fundamentos de Filosofía del Derecho, Barcelona, 1961, p. 186.

42 Obra citada, p. 82. 
En cualquier caso los criterios de la justicia siguen siendo poco nítidos: el conformar las desigualdades económicas de forma que sean ventajosas para todos no supone una respuesta a los interrogantes concretos que puedan plantearse a la vista de una norma específica. Tal vez habría que observar que si la constitucionalidad o no de una ley no es fácil de determinar, a pesar de la existencia de una constitución escrita, mucho más lo es el precisar si la misma ley se adapta o no a los principios de la justicia que no están, por esencia, escritos en ningún texto positivo.

No obstante sí pueden darse algunas pistas o criterios; y así Lumier señala que los dos principios que deben guiar la búsqueda de la justicia son la seguridad y la libertad (tomando como equivalentes libertad e igualdad).

La posibilidad de invocar tales principios puede darse en algunos ordenamientos jurídicos y así puede mantenerse que en nuestro derecho, y en la mayoría de las constituciones políticas de los Estados democráticos se pueden dar y sustento a la invocación de tales valores, basándose en los principios en los que se funda la constitución; y que en el ámbito internacional podrían encontrar su apoyo en el convenio europeo para la protección de los derechos humanos y en la declaración universal de derechos humanos.

Por ello es posible que dentro del propio ordenamiento jurídico y de la constitución ${ }^{43}$ encontremos una base para tachar de injusta una ley.

Ahora bien, tal alegación no siempre será efectiva, ya que determinadas leyes - un ejemplo pueden ser la del exterminio de los judíos en la época nazi- claramente injustas eran coherentes con el ordenamiento jurídico en el marco del cual eran dictadas, sin que tampoco existiera una constitución que las desautorizara.

En tal hipótesis tendríamos que referirnos a un concepto de justicia por encima de cualquier tipo de derecho positivo, enlazando con el derecho natural. Como señala Hegel ${ }^{44}$ :

«Cuando al derecho positivo y las leyes se oponen el sentimiento del corazón, las inclinaciones y el arbitrio, no será la filosofía quien reconozca tales autoridades. Que la fuerza y la tiranía pueden ser un elemento del derecho positivo, es para el contingente y no pertenece a su naturaleza».

El contenido del derecho natural así como su propia existencia ha sido objeto, como queda indicado de amplias controversias a través de

43 Además de poderla atacar por anticonstitucionalidad que es alegación diferente.

44 Principios de filosofía del derecho, Barcelona, 1988, p. 58. 
la historia: admitido por Aristóteles ${ }^{45}$, Cicerón, el derecho romano y la escolástica fue rechazado por el positivismo. Aunque, con todos sus inconvenientes e imprecisiones, parece el único punto de apoyo contra los posibles excesos de un derecho despótico, la incertidumbre de su contenido, e incluso la negación de su existencia, nos llevan a preguntar si la finalidad del derecho natural no puede ser reemplazada por los principios generales del derecho.

\section{Los principios generales del derecho}

La fijación de los principios generales del derecho es controvertida: Cicerón indicó que los principios generales del derecho no eran los del derecho vigente, sino superiores a ellos e íntimamente relacionados con los principios filosóficos ${ }^{46}$; determinados códigos civiles hacen referencia explícita a los principios generales del derecho.

Desde esta perspectiva los problemas existentes en torno a la existencia y contenido del derecho natural de alguna forma se trasladan a la fijación de los principios generales del derecho, siendo, en el fondo, la elección de derecho natural o principios generales del derecho como criterios últimos en que fijar el concepto de justicia una cuestión más semántica que de contenido real; pero que al menos en nuestro ordenamiento jurídico tiene la ventaja de basarse en una norma concreta en cuanto a su posible aplicación, cuál es el artículo 1.4 del Código Civil; aun cuando no puede dejarse de notar la paradoja que ello pueda suponer al tratar de encuadrar dentro del ordenamiento positivo unos fundamentos del derecho que se suponen están, por esencia, encima y al margen de tal ordenamiento.

En tal sentido, por ejemplo, se pronunció García Valdecasas ${ }^{47}$, que señalaba cómo los principios generales del derecho «están en toda fuente del Derecho y, por tanto, no habrá propiamente una superioridad de la ley entre ellos, pues el sentido de la ley tiene que ser conforme a los principios generales del Derecho».

Precisa a este respecto Elías de Tejada ${ }^{48}$ :

«No se trata de la baladí archisabida minucia de saber si es anterior el huevo a la gallina o viceversa. Es que si son principios filosófi-

45 Etica a Nicómaco, libro V, capítulo VII.

46 De legibus I, IV, 17.

47 El problema de las fuentes del derecho, Conferencia en la Universidad de Deusto, 1955 , p. 13

48 «Los principios generales del derecho en el art. 1 del Código Civil reformado en 1973», en Estudios sobre el título preliminar del Código Civil, vol. I, Madrid 1977, p. 92. 
cos además de informar al ordenamiento jurídico estarán por encima de él, y servirán para medirlo y en su caso corregirlo. Mientras que si no son reconocidos más que los principios de que ya informan a la ley y a la costumbre carecerán de autonomía, y estarán encarcelados en la cárcel del mismo ordenamiento vigente».

En derecho comparado la referencia a los principios generales del derecho existen varios ordenamientos: así el Código Civil austriaco refiriéndose en su artículo 7 al derecho natural, y el Código Civil italiano de 1865 el cual parece ser pasó a nuestro Código Civil.

En la configuración de los principios generales del derecho además de los dos puntos de vista antagónicos que los refieren respectivamente al derecho natural o al de los principios que se deducen del conjunto del ordenamiento ha habido otras posiciones intermedias, como la de Del Vecchio que pretende sustituirlos por los del derecho romano - si bien teniendo al derecho romano como expresión y cristalización del derecho natural- o eclécticas, como la de Albaladejo ${ }^{49}$ que señala que los principios generales del derecho son «las ideas fundamentales que informan nuestro Derecho positivo contenido en Leyes y costumbres y, en última instancia aquellas directrices que derivan de la justicia tal y como se entiende por nuestro ordenamiento jurídico». Mientras que para Helmunt Coing ${ }^{50}$ :

«La idea del derecho es, según esto, la suma de los contenidos morales (valores) que están ligados al desarrollo del derecho».

Alguna sentencia del Tribunal Supremo dictada bajo la redacción primitiva del Código Civil ha manifestado incluso que a él le está encomendada «la elevada misión de aplicar los principios generales del derecho» ${ }^{51}$.

La jurisprudencia anterior a la reforma del Código Civil había señalado que los principios generales del derecho sólo son aplicables cuando se alegan en defecto de Ley y de costumbre ${ }^{52}$, que no lo son las opiniones de los tratadistas ${ }^{53}$, y que deben estar reconocidos como tales en la ley y en la doctrina legal para que puedan servir de base a un recurso de casación ${ }^{54}$, incluso señalando que hace falta más de una sola sentencia del Tribunal Supremo que lo reconozca ${ }^{55}$.

\footnotetext{
49 Derecho Civil, tomo I, Barcelona, 1975, p. 93.

50 Fundamentos de filosofía del derecho, Barcelona, 1961, p. 158.

51 S. 12 de junio de 1926.

52 Ss. entre otras de 18 de marzo de 1931, Ar. 1.978 y 4 de junio de 1964, Ar. 3.876.

53 S. 31 de octubre de 1953, Ar. 2.914.

54 Ss. 3 de diciembre de 1928 y 10 de junio de 1966, Ar. 3.026.

55 Ss. 14 de marzo de 1953, Ar. 1.619 y 14 de mayo de 1964, Ar. 3.876.
} 
Ciertamente la antigua redacción del art. 1.691.1 de la Ley de Enjuiciamiento Civil que señalaba como motivo de recurso de casación el que el fallo contenga dilación, interpretación errónea o aplicación indebida de las leyes o doctrinas legales aplicables al procedimiento objeto del recurso.

La no inclusión como motivos del recurso de la violación de los principios generales del derecho y sí de la doctrina legal ha podido contribuir a la equiparación de doctrina legal con principios generales del derecho reconocidos y, en definitiva, a hacer pasar a aquéllos por el filtro de la jurisprudencia.

Se ha criticado tal interpretación señalando que el Tribunal Supremo no es quien para buscar los principios generales del Derecho que estarán no en su sede, sino que son patrimonio de los filósofos del derecho ${ }^{56}$.

Como es sabido el artículo 1.4 del Código Civil en su actual redacción señala:

«Los principios generales del derecho se aplicarán en defecto de ley o costumbre sin perjuicio de su carácter informador del ordenamiento jurídico» ${ }^{57}$.

Mientras que en su primitiva redacción el artículo 6.2 del Código Civil indicaba que «cuando no haya Ley exactamente aplicable al punto controvertido se aplicará la costumbre del lugar y, en su defecto, los principios generales del Derecho».

La nueva redacción del título preliminar del Código Civil no señala, como subraya Batlle ${ }^{58}$, a qué principios generales del derecho se aluden; y la supresión del texto inicial del artículo 1.691.1 de la Ley de Enjuiciamiento Civil ${ }^{59}$ puede abonar más la interpretación amplia de los principios generales del derecho no limitándolos a los del ordenamiento jurídico vigente, y en ese sentido, rechazando la limitación que supondría tener en cuenta solamente tales principios, se ha pronunciado Díez Picazo ${ }^{60}$.

Después de la modificación del Código Civil el Tribunal Supremo ha continuado exigiendo la necesidad de que tales principios hayan sido recogidos por la jurisprudencia para que puedan dar pie a la casación ${ }^{61}$.

56 Elías de TeJAdA, obra citada, p. 94.

57 Tal redacción fue introducida por la Ley de 17 de marzo de 1973.

58 Comentarios al Código Civil, tomo I, Madrid, 1978, p. 56.

59 El artículo 1.692.4. ${ }^{\circ}$ de la Ley de Enjuiciamiento Civil que es el texto sustitutorio señala: «Infracción de las normas del ordenamiento jurídico o la jurisprudencia que fueren aplicables para resolver las cuestiones objeto de debate».

60 En Comentarios al Código Civil, Madrid, 1991, tomo I, p. 11.

61 Ss. 7 de febrero de 1972, 12 de junio de 1980, Ar. 2.404 y 22 de febrero de 1993, Ar. 1.218 entre otras. 
Lo que también ha precisado el Tribunal Supremo es que los principios generales del derecho sólo se aplicarán en defecto de ley o costumbre ${ }^{62}$, cercenando de esta forma el propio contenido del artículo 1.4 del Código Civil e insistiendo en esta postura después de la reforma del título preliminar del mismo; ya que de acuerdo con el nuevo artículo 1 no sólo se aplican en defecto de ley o de costumbre, como antes señalaba el artículo 6 de dicho cuerpo legal: el carácter informador del ordenamiento jurídico que contiene la redacción actual del artículo 1.4 parece haber sido olvidado por el Tribunal Supremo, que no lo ha reconocido en los fallos tenidos con posterioridad a la modificación del título preliminar del Código Civil.

Cuestión distinta e importante es la de la posible modificación de los principios generales del derecho por la promulgación de la Constitución y la interacción entre ésta y aquéllos.

Se ha dicho ${ }^{63}$ que la «mutación de los principios políticos supone necesariamente una mutación de todo el ordenamiento jurídico»; y tal axioma es sobre todo aplicable cuando se trata de los principios generales del derecho.

Por eso se ha planteado el problema de entender si los principios generales del derecho al que alude el artículo 1 del Código Civil, deben ser los contenidos en la Constitución y que éstos deben ser aplicables a todo el ordenamiento jurídico.

Algún sector de la doctrina ha entendido que la Constitución de 1978 no recoge unos principios políticos determinados y que por tanto no es posible deducir de la misma unos principios de aplicación general para el ordenamiento jurídico dada la ambivalencia de sus preceptos que pueden servir tanto a una sociedad capitalista como a una sociedad socialista ${ }^{64}$.

No obstante y a pesar del sentido ambiguo que se le pueda dar al artículo 9.2 de la Constitución, piedra de toque de posibles interpretaciones contradictorias, lo que no parece discutible es la incorporación de una serie de valores tales como la libertad, la justicia y la igualdad al ordenamiento jurídico en virtud del artículo 1.1 y del propio 9.3 de

62 S. 30 de octubre de 1976. Batlle en Comentarios al Código Civil, tomo I, Madrid, 1978, p. 56, critica esta actitud del Tribunal Supremo que exige de manera inexplicable, según él, la prueba de la inexistencia de Ley o de costumbre.

63 GonzÁlez Pérez, Jesús, «Los principios generales del derecho y la Constitución» en La Constitución Española y las fuentes del Derecho, Madrid, 1979, vol. II, p. 1.164.

${ }^{64}$ Véase DíEz PicAzo, «Constitución española y fuente del Derecho» en Cívitas, Revista Española de Derecho Administrativo n. ${ }^{\circ}$ 21, pp. 190 y ss., también GonZÁLEZ PéREZ, obra citada en nota anterior, p. 1.166 que analiza la experiencia italiana en el llamado caso alternativo del derecho. 
la Constitución, en definitiva la configura como Estado de derecho65: es más, la propia existencia de la Constitución en un sentido ontológico, como subraya Karl Loewenstein, supone una concepción que acepta la limitación y el control de poder ${ }^{66}$.

El propio Tribunal Constitucional ha resaltado el valor de la justicia como informador del ordenamiento jurídico, de acuerdo con el artículo 1 de la Constitución ${ }^{67}$.

Lucas Verdú ${ }^{68}$ señala como características del estado de derecho:

«Considero que una descripción más amplia de lo que sea el Estado de Derecho, que abarca las observaciones anteriores sería ésta: Cuando un Estado configura, jurídicamente, la organización y ejercicio de los poderes públicos, de manera que los individuos y sus grupos estén protegidos por la existencia previa de normas e instituciones garantizadoras de sus derechos y libertades».

¿Se pueden indicar tales principios como generales del derecho básico del ordenamiento jurídico ${ }^{69}$ ?

El Tribunal Constitucional parece haberlo entendido así. La sentencia de 4 de octubre de $1970^{70}$ señala:

«Cada norma singular no constituye un elemento aislado e incomunicado en el mundo del Derecho, sino que se integra en un ordenamiento jurídico determinado, en cuyo seno, y conforme a los principios generales que lo informan y sustentan, deben resolverse las antinomias y vacíos normativos, reales o aparentes, que de su articulado resulten. Sólo si, en el contexto ordinamental en que se inserta y teniendo en cuenta las reglas de interpretación admisibles en Derecho, el contenido o las omisiones de un texto normativo produjeran confusión o dudas que generarán en sus destinatarios una incertidumbre razonablemente insuperable acerca de la conducta exigible para su cumplimiento o sobre la previsibilidad de sus efectos, podría concluirse que la norma en cuestión infringe el principio de seguridad jurídica».

Y no solamente lo ha entendido así, sino que el Tribunal Constitucional subraya la doble función de los principios generales del derecho ex-artículo 1 del Código Civil que había sido olvidada por el Tribunal Supremo:

65 Véase Garrido Falla, Comentarios a la Constitución, Madrid, 1980, p. 25.

${ }^{66}$ Loewenstein, K., Teoría de la Constitución, Barcelona, 1964, p. 151.

67 Auto 251/84, de 25 de abril J .C. tomo VIII .

68 En Constitución Española de 1978, tomo I, p. 45, Madrid, 1.983.

69 En tal sentido véase BACHOF, Jueces y Constitución, Madrid, 1963, pp. 25 y ss.

70 STC 150/1990, de 4 de octubre (Pleno) BJC nov. de 1990, p. 5 
«Los principios generales del Derecho incluidos en la Constitución tienen carácter informador de todo el ordenamiento jurídico —como afirma el artículo 1.4, del título preliminar del Código Civil- que debe así ser interpretado de acuerdo con los mismos. Pero es también claro que allí donde la oposición entre las leyes anteriores y los principios generales plasmados en la Constitución sea irreductible, tales principios, en cuanto forman parte de la Constitución, participan de la fuerza derogatoria de la misma, como no puede ser de otro modo. El hecho de que nuestra norma fundamental prevea en su artículo 53.2, un sistema especial de tutela de las libertades y derechos - reconocidos entre otrosen el artículo 14, que se refiere al principio de igualdad, no es sino una confirmación de carácter específico del valor aplicativo - y no meramente programático- de los principios generales plasmados en la Constitución.

En conclusión, en los supuestos en que exista una incompatibilidad entre los preceptos impugnados y los principios plasmados en la Constitución, procederá declararlos inconstitucionales y derogados, por ser opuestos a la misma ${ }^{71}$.

También hay que resaltar que el Tribunal Supremo, que anteriormente no había recalcado el principio ordenado del ordenamiento jurídico y de los principios generales del derecho, lo ha retomado a partir de la jurisprudencia citada del Tribunal Constitucional ${ }^{72}$.

Ciertamente tal reconocimiento no es siempre uniforme y parece efectuarlo el Tribunal Supremo a regañadientes, porque en otras ocasiones, y tal vez más numerosas sigue insistiendo en el carácter exclusivamente supletorio de los principios generales del derecho:

«...el fundamento del principio general del derecho alegado aparece claramente reconocido en el art. 1.257 CC, lo que da lugar a que según la doctrina de esta Sala no pueda ser admitido, por cuanto dado el rango jerárquico que les confiere el art. 1.1 CC, solamente pueden ser citados con éxito a falta de normas legales o consuetudinarias ${ }^{73}$ ».

Como puede verse, el Tribunal Constitucional se basa también en el artículo 53.2 de la Constitución para llegar a esa solución; artículo que señala la tutela de las libertades y derechos reconocidos en el artículo 14 y en la sección 1. a. Pero esta constitucionalización de los principios de la justicia no está exenta de riesgos: riesgos que ya los proclamó Hamilton en los primeros tiempos de la independencia de los Estados Unidos:

71 STC 2 de febrero de 1981, RI-1 BJC mayo 1981, p. 7.

72 S. del T.S. de 21 de abril de 1988, Ar. 3.268.

73 S. 12 de mayo de 1992, Ar. 3.920. 
«Estrictamente hablando, el pueblo no abandona nada en este caso, y como lo retiene todo, no necesita reservarse ningún derecho en particular. "Nosotros, el pueblo de los Estados Unidos, con el objeto de asegurar los beneficios de la libertad a nosotros mismos y a nuestros descendientes, estatuimos y sancionamos esta Constitución para los Estados Unidos de América". Aquí tenemos un reconocimiento de los derechos populares superiores a varios volúmenes de esos aforismos que constituyen la distinción principal de las declaraciones de derechos de varios de nuestros Estados, y que sonarían mucho mejor en un tratado de ética que en la constitución de un gobierno, [...]. Voy más lejos y afirmo que las declaraciones de derechos, en el sentido y con la amplitud que se pretenden, no sólo son innecesarias en la Constitución proyectada, sino que resultarían hasta peligrosas. Contendrían varias excepciones a poderes concedidos y por ello mismo proporcionarían un pretexto plausible para reclamar más facultades de las que otorgan. ¿Con qué objeto declarar que no se harán cosas que no se está autorizado a efectuar? Por ejemplo: ¿para qué se afirmaría que la libertad de la prensa no sufrirá menoscabo, si no se confiere el poder de imponerle restricciones? No es que sostenga que una disposición de esa clase atribuiría facultades de reglamentación; pero es evidente que suministraría a los hombres con tendencias usurpadoras una excusa atendible para reclamar ese poder. Podrían argumentar con cierta apariencia de razón que no se debe imputar a la Constitución el absurdo de precaverse contra el abuso de una potestad que no existe y que la disposición que prohíbe limitar la libertad de la prensa autoriza claramente a inferir la intención de dotar al gobierno nacional de la facultad de prescribir normas apropiadas en el caso de dicha libertad. Esto puede servir de ejemplo de los numerosos asideros que se ofrecerían a la doctrina de los poderes de interpretación si se transige con este imprudente celo en favor de las declaraciones de derechos» ${ }^{74}$.

Como agudamente observó Hamilton el refrendar mediante una ley positiva, por muy importante que fuera ésta, ciertos derechos que se suponen son preexistentes al ordenamiento jurídico y connaturales por su existencia al hombre, tiene el peligro de encerrar a éstos dentro de la «jaula de oro» del ordenamiento jurídico positivo y por ello se ha dicho que «lo que es verdaderamente fundamental, por el mero hecho de serlo, nunca puede ser puesto, sino que debe ser simple presupuesto» ${ }^{75}$.

No obstante como el propio Zagrebelsky reconoce ${ }^{76}$ :

74 Hamilton, El Federalista, México, 1943, p. 376.

75 Zagrebelsky, Gustavo: El derecho dúctil, ley, derechos, justicia, Madrid, 1996, p. 9 .

76 Obra citada, p. 115. 
«Se podría incluso decir que las Constituciones reflejan el "orden natural" histórico-concreto de las sociedades políticas secularizadas y pluralistas, en las que, precisamente por ello, no podría proponerse de nuevo un derecho natural con fundamento no teológico ni racionalista».

En definitiva a pesar de los peligros de concretar en unos principios determinados los principios generales de la justicia y del derecho natural, lo que sí puede admitirse es su reconocimiento por la constitución, o por diversas constituciones; siempre que tengamos muy en cuenta que este reconocimiento no supone que la existencia de los mismos se debe al hecho jurídico de su inclusión en el catálogo de derechos constitucionales, ni que tal catálogo sea limitativo de los derechos y, por tanto, sin que quepa argüir que los que no están en la constitución o en el «bill of rights» no existen.

\section{Conclusiones}

De la doctrinal del Tribunal Constitucional puede deducirse que los principios generales del derecho para dicho Tribunal:

a) Son los que contiene la Constitución.

b) Que para ello el Tribunal Constitucional no se para a enumerar cuáles son tales principios, aunque sí subraya el valor superior de la libertad ${ }^{77}$ y que la igualdad es uno de los valores superiores ${ }^{78}$.

c) Que puntualiza que son de aplicación directa.

d Que deben ser informadores del ordenamiento jurídico.

e) Que tienen una virtud derogatoria de las leyes que se opongan a los mismos.

Con tal interpretación los principios generales del derecho quedan realzados, porque no se trata solamente de ser fuente supletoria, sino de ser fuente informadora de la totalidad del ordenamiento jurídico, pudiendo llegar a la derogación de aquellas normas preconstitucionales que se le opongan.

Incluso podíamos hablar de unos principios constitucionales europeos en el ámbito de la Unión Europea y del convenio europeo para la protección de los derechos humanos y libertades fundamentales de 4 de noviembre de 1950, ámbito más genérico y tal vez más impreciso pero no por ello inexistente.

77 STC 132/1989, de 18 de junio, R-I-93, BJC sep. 1989, p. 1.245.

78 STC 216/1991, de 14 de noviembre, RA 1.844/1988, BJC dic. 91, p. 43. 
¿Es ésta la solución? ¿Hemos de decir que los principios generales del derecho son exclusivamente los contenidos en la Constitución; o como máximo los contenidos en la Constitución y en los tratados que forman la Unión Europea y el entramado de instituciones europeas? Estimo que tal concreción no es suficiente y puede de alguna forma cercenar y empobrecer los principios generales del derecho: pero, no obstante, la referencia a los principios de libertad y justicia contenidos en la Constitución como valor informador de la totalidad del ordenamiento jurídico supone un paso adelante sobre la mera aplicación de los principios generales del derecho contenidos en el propio ordenamiento jurídico, a los que anteriormente aludía el Tribunal Supremo.

Ello no significa que la concreción a un ordenamiento jurídico determinado no tenga siempre los peligros de limitación en el espacio y en el tiempo: en el espacio porque donde la Constitución no garantiza esos principios no existe tal módulo de referencia en el tiempo por la misma razón a los períodos históricos en que la normativa básica ha sido diferente, razones que nos hacen abonar el concepto tradicional de los principios generales del derecho fundados en el derecho natural o en la idea de la justicia —más abstracta pero también más universal y menos controvertida - como base del ordenamiento jurídico. 